\title{
TESTE E CERTIFICAÇÃO DE EMISSÕES DE VEÍCULOS: DETECÇÃO DE DISPOSITIVOS INDESEJÁVEIS
}

\author{
Fábio C. Branco, Gabriel M. Branco \\ EnvironMentality \\ fabio.tcl@uol.com.br, gabriel.tcl@uol.com.br
}

\begin{abstract}
The recent global discussion of the vehicle emission compliance with the environmental requirement, known as "dieselgate", demands enhanced criteria to evaluate the engine behavior in real driving conditions and in standard driving cycles. This comparison might demonstrate the existence of bias or different behaviors in dynamometer and real traffic, which characterize a defeat device.
\end{abstract}

Type approval certification requires vehicle testing under driving conditions statistically representative of the real traffic, as established in the law through a standard driving cycle. However, vehicle electronic management allows for adaptive behavior to optimize calibration to each customer driving style, and so to the test requirement as well, which impair the representativeness of the test vehicle itself.

Measuring the exhaust emissions and downloading the operational parameters from the engine CAN are the key for testing the vehicle along a real route, provided the representativeness of vehicle speed and acceleration in the test is statistically checked. Engine parameters and instant emissions are analyzed to identify similarities in their statistical distributions, both in the legal test cycle and the street.

An extensive data bank is collected along many routes under normal traffic, to recreate the engine map, by recalculating the emissions and fuel consumption averages in the legal driving cycle from real traffic data.

\section{RESUMO}

A recente discussão global sobre a desconformidade de veículos com a exigência ambiental, conhecida como "dieselgate", exige melhores critérios para avaliar o comportamento do motor em condições reais de condução e em ciclos padrão. Esta comparação demonstrará a existência de viés ou diferentes comportamentos em dinamômetro e tráfego real, o que caracteriza um dispositivo indesejável.

A certificação de tipo requer testes de veículos sob condução estatisticamente representativa do tráfego real, estabelecido na lei por meio de um ciclo de condução padrão. No entanto, a gestão eletrônica do veículo permite um comportamento adaptativo para otimizar a calibração para cada estilo de condução do cliente, bem como para as condições de ensaio, o que prejudica a representatividade do próprio veículo de teste.

Medir as emissões de escape e registrar os parâmetros operacionais do motor lidos na CAN são a chave para testar o veículo em uma rota real, desde que se verifique a representatividade estatística da velocidade e da aceleração do veículo no ensaio. 
Parâmetros do motor e emissões instantâneas são analisados para identificar semelhanças em suas distribuições estatísticas, tanto no ciclo padrão como na rua.

Um extenso banco de dados é coletado ao longo de várias rotas sob tráfego normal, para recriar o mapa do motor, recalculando as médias de emissões e consumo de combustível no ciclo padrão, a partir de dados de tráfego real.

\section{Histórico: controle da poluição do ar e certificação de tipo}

$\mathrm{Na}$ medida em que as frotas urbanas ultrapassaram as centenas de milhares de veículos, a poluição do ar tornou-se importante, sendo esta a maior fonte de emissões nas grandes cidades. Para o seu controle é necessário que os veículos sejam fabricados com tecnologias especiais e certificados para demonstrar 0 atendimento e a conformidade do projeto com limites de emissão estabelecidos.

A poluição do ar é um fenômeno essencialmente estatístico e seu controle deve ser dimensionado pelas médias das emissões, isto é, ponderando-se os seus valores pontuais pela frequência estatística de ocorrência. Por isso, os ensaios de emissão devem ser representativos da realidade nos seguintes aspectos principais:

- dos hábitos da sociedade ou da maneira de dirigir nas condições reais de tráfego;

- das características físicas e construtivas do veículo ensaiado;

- das reações e do comportamento do veículo nas ruas em movimentos reais.

Como a emissão de poluentes por um veículo depende da solicitação do motor, o procedimento de certificação é baseado na sua condução segundo um ciclo padrão de velocidades em função do tempo, representativo das condições de tráfego e dos hábitos médios da sociedade em geral. Estes ensaios não se baseiam em regimes médios, mas em estatísticas representativas do comportamento dos veículos e de seus motoristas, incluindo regimes extremos, agressivos ou suaves, na proporção das suas ocorrências no uso normal. No Brasil, o ciclo oficial é o FTP $75^{i}$ norteamericano $^{(1)}$ e os limites de emissão regulamentados referem-se às condições estatísticas representadas neste ciclo.

O veículo submetido aos testes deve ser representativo do modelo a ser comercializado e as suas características de massa, resistência ao rolamento e aerodinâmica são simuladas em um dinamômetro especialmente calibrado para isso.

\section{A ocorrência de fraudes na certificação}

Enquanto os veículos eram essencialmente compostos por sistemas mecânicos, a representatividade do exemplar submetido a testes era conferida contra seus desenhos para garantir a sua representatividade no processo de certificação.

Entretanto, com a sofisticação dos controles adaptativos automáticos, as reações e o comportamento do veículo podem ser amplamente alterados pelo próprio sistema de gerenciamento eletrônico, comprometendo a representatividade do ensaio em laboratório em relação às condições reais de uso de toda a frota daquele modelo e,

\footnotetext{
${ }^{1}$ Neste trabalho, a referência FTP refere-se ao ciclo urbano do Federal Test Procedures, idêntico ao definido na norma ABNT NBR 6601 com 1372 segundos; FTP 75 refere-se ao ciclo FTP repetido com partidas a frio e a quente, cujos resultados são ponderados conforme a norma citada.
} 
consequentemente, perdendo a garantia da proteção ambiental e da saúde pública. Em outras palavras, certas alterações automáticas de calibração podem modificar o comportamento do veículo durante o ensaio padronizado, tornando-o não representativo dele mesmo nas condições de uso normal. São os chamados dispositivos indesejáveis ao controle de emissão ou "defeat devices".

É importante considerar que existem sistemas auxiliares para situações de emergência que podem reduzir momentaneamente os controles de emissão e são permitidos mundialmente, desde que declarados, caracterizados e justificados pelo fabricante e que não atuem nas situações normais e mais frequentes ou sua atuação esteja presente nos ensaios oficiais.

O uso indiscriminado desses sistemas, especialmente se ativados para reduzir as emissões apenas nos ensaios laboratoriais, caracterizam fraude ao processo de certificação do veículo. Tais fraudes se baseiam no reconhecimento de características típicas dos ensaios em laboratório, como por exemplo, o veículo funcionando com duas rodas paradas, ou com a direção imóvel, ou ter percorrido um ciclo padrão e ter ficado parado nas 12 horas seguintes, ou outras formas de identificar a condição de teste.

Portanto, torna-se necessária a realização de ensaios complementares aos oficiais, dotados de novos critérios e aprimoramentos que avaliem a representatividade das condições de teste a partir das respostas do veículo, com a isenção necessária para evitar condições extremas de solicitação, sejam elas artificiosamente abusivas ou favoráveis, ou considerá-las com a ponderação pela devida proporção de suas ocorrências entre os milhões de quilômetros rodados anualmente por toda a frota.

Nesse sentido, a Resolução CONAMA no 230/1997ii (IBAMA, 2011) estabelece, no seu artigo $4^{\circ}$, que:

O IBAMA poderá testar ou requerer testes de quaisquer veículos, em local por ele designado, com o objetivo de investigar a eventual presença ou efeito de "itens de ação indesejável"

$\S 1^{\circ}$ Na realização dos testes mencionados no caput deste artigo, o IBAMA poderá utilizar quaisquer procedimentos e condições de ensaio que possam ser esperados durante a operação em uso normal do veículo automotor (grifo nosso).

Tais aprimoramentos nos procedimentos de ensaio serão necessários para assegurar que o veículo em teste mantenha a sua própria representatividade em relação ao uso em campo, ou para verificar a existência de viés no comportamento do sistema de gerenciamento do motor nessas condições.

A investigação de suspeitas de fraudes na conformidade com os regulamentos ambientais, no comportamento de veículos durante o uso normal, precisa ser baseada em ensaios não padronizados, para impossibilitar o seu reconhecimento pelo sistema de gerenciamento do motor. Por outro lado, esta despadronização levanta dúvidas sobre a representatividade das solicitações de carga impostas ao veículo e, consequentemente, dos resultados obtidos. 


\section{Ensaios em tráfego real}

A modernização dos equipamentos para a medição de emissões permitiu a criação de equipamentos portáteis PEMS (Portable Emission Measurement Systems), que podem ser alojados no porta-malas do veículo. Estes equipamentos fazem a amostragem dos gases de escapamento, medem sua vazão e registram os resultados em frequências de 5 a $10 \mathrm{~Hz}$, suficientes para detectar as variações do movimento do veículo, do comportamento do motor e dos gases de escapamento iii. Adicionalmente é possível registrar também a velocidade do veículo detectada por um GPS e os parâmetros de calibração do motor a partir do conector do OBD.

$\mathrm{Na}$ Europa, são escolhidos percursos reais para a realização de testes, porém as regras estabelecidas para isso nas suas Diretivas (regulamento EU 2016/427 ${ }^{\mathrm{iv}}$ ) não asseguram nem mesmo verificam adequadamente as condições de representatividade do trajeto em relação aos hábitos da sociedade.

A EPA (CFR 40 Part $86 \S 86.1809-10^{v}$ ), utiliza o conceito de que o "trajeto real" deve "conter movimentos razoavelmente esperados no uso e em operação normais", para investigar a possível presença de um defeat device. Como os ciclos de condução adotados nos ensaios oficiais são considerados os mais representativos dos hábitos médios de toda a sociedade, tal como estabelecido na legislação, o comportamento do veículo no trajeto real deve ser estatisticamente semelhante ao dos ciclos oficiais de condução adotados. Tal comportamento inclui as condições de tráfego e velocidade, a forma de dirigir (movimentos do pedal do acelerador, troca de marchas etc.) e as respostas do motor.

Este conceito é muito apropriado porque as exigências legais para a conformidade de projeto se baseiam nos ensaios realizados com os ciclos de ensaio FTP 75 e Highway' ${ }^{2}$, assumidos como representativos dos hábitos da sociedade, por definição. Por isso, a validação de um trajeto real para um ensaio de verificação RDE - "Real Driving Emissions" deve comprovar a semelhança das distribuições estatísticas dos parâmetros de controle e de resposta do motor, da velocidade e aceleração do veículo, RPM, torque, fluxos de ar, de combustível e de escapamento etc., bem como de algumas relações importantes entre eles.

É importante considerar que os ensaios feitos em tráfego real agregam condições mais severas do que os testes realizados em dinamômetro, em razão da existência de forças decorrentes de ventos, aclives, declives, curvas, vias em mau estado e outras interferências no movimento que não são passíveis de serem transferidas ao dinamômetro.

Também é necessário ressaltar que a variabilidade do tráfego impede que dois ensaios realizados no mesmo circuito apresentem a mesma série temporal de eventos, de velocidades e, portanto, dos demais parâmetros medidos. Por esta razão, o tratamento dos resultados obtidos deve ser sempre estatístico e não segundo a sequência temporal, para afastar eventuais dúvidas levantadas sobre a sua validade.

\footnotetext{
${ }^{2}$ Nos EUA foi adotado o ciclo US06 como ensaio complementar, mais agressivo, que representa as acelerações mais severas resultantes da maior agilidade dos motores e transmissões mais modernos.
} 


\section{Metodologia}

A metodologia para a identificação e caracterização de um dispositivo de ação indesejável exige procedimentos específicos e sem padronização sequencial de movimentos, com o objetivo de avaliar o comportamento do motor e suas respostas nas condições reais de tráfego, em percursos e situações validados para evitar questionamentos sobre os resultados e as conclusões dos ensaios.

Em primeiro lugar, será necessário comprovar que os ensaios realizados representam a forma de utilização normal dos veículos pela sociedade em termos de tráfego, maneira de dirigir, condições atmosféricas etc.. Mesmo assim, os resultados obtidos diretamente de um percurso em tráfego real são relativos àquele percurso em particular e podem diferir de outros percursos igualmente válidos, não devendo ser utilizados como definitivos sem a realização de ensaios em várias rotas diferentes. Esta é uma das principais dificuldades para a aceitação dos ensaios $\mathrm{RDE}$, pois é necessário estabelecer uma faixa de tolerância para as variabilidades da rota para distingui-las da atuação de um defeat device.

Em segundo lugar, será necessário correlacionar os parâmetros de calibração do motor, lidos diretamente do sistema eletrônico de gerenciamento, com as medidas de emissão e de consumo de combustível, cruzando dados internos do motor com externos dos equipamentos de medição PEMS e GPS.

Finalmente, será necessária uma análise segura que distinga a variação de comportamento dos sistemas de controle de emissão em regimes transitórios, aceita como estratégia auxiliar de calibração, da atuação desta mesma estratégia como dispositivo indesejável de controle de emissão.

\subsection{Escolha e validação do percurso para ensaio}

O percurso a ser seguido durante os ensaios em trânsito deve ser escolhido de forma a ser representativo das condições estatísticas do ciclo oficial de condução que, por sua vez, representam o comportamento médio da sociedade reconhecido pela regulamentação. Com o auxílio do aplicativo Google Maps, é fácil escolher trajetos reais na cidade que apresentem distâncias e velocidades médias semelhantes às do ciclo oficial. Após a realização de cada ensaio no percurso escolhido será necessário validar o comportamento estatístico dos movimentos efetivamente presentes no ensaio, comparando-o com o do ensaio oficial.

Um método simples e eficaz para a validação de um percurso, segundo o conceito da EPA, é a comparação dos histogramas tridimensionais levantados para a matriz das combinações de velocidade e aceleração encontradas, considerando o percurso escolhido e os ciclos de condução oficiais. As figuras a seguir apresentam o caso real de um trajeto levantado em São Paulo, Brasil, e os três principais ciclos de condução internacionais. Estes gráficos evidenciam que o trajeto escolhido ainda carece de velocidades mais elevadas (freeways) para representar totalmente o ciclo FTP 75, adotado no Brasil, bem como indica a precariedade do ciclo NEDC (New European Driving Cycle) e a riqueza de movimentos do novo ciclo harmonizado WLTC (World Light duty Test Cycle), criado a partir de um levantamento estatístico realizado em mais de 800 mil $\mathrm{km}$ de percursos em vários países ${ }^{\mathrm{vi}}$, que está em fase de adoção internacional. É importante salientar a conveniência de o ciclo oficial ser tomado como referência dos hábitos da sociedade, tal é a extensão dos trabalhos 
para a sua elaboração, bem como por ser a referência oficial já exigida na fabricação dos veículos.

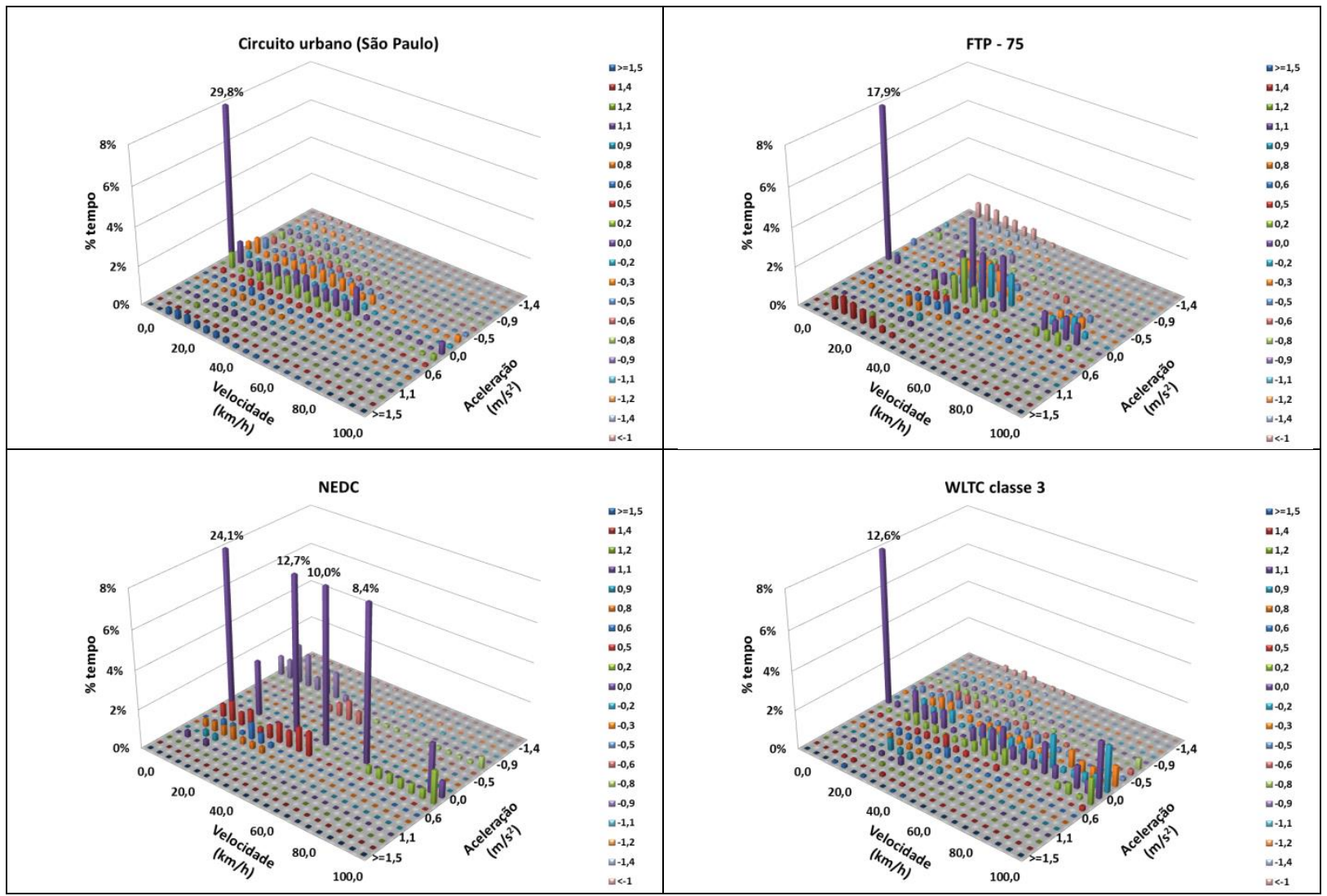

Figura 1 - Aspectos estatísticos dos ciclos de condução e do tráfego real

\subsection{Verificação da representatividade da maneira de dirigir}

Nos ciclos padronizados em dinamômetro, o motorista conhece previamente a sequência dos movimentos e não sofre interferências externas, enquanto que nos realizados em trânsito real, ocorrem situações improvisadas e dependentes de fatores externos.

A avaliação do comportamento do motorista nos ensaios é fundamental para verificar a sua representatividade, particularmente em termos da agressividade nas acelerações e dos hábitos de trocas de marcha, os quais podem exercer influência significativa sobre os resultados de um ensaio e devem ser monitorados.

Tal comportamento pode ser observado a partir das curvas temporais de velocidade, aceleração, RPM, consumo instantâneo, movimentação do pedal do acelerador e velocidades nas trocas de marcha, que podem ser obtidos a partir da leitura da rede CAN. A avaliação das curvas mencionadas é realizada a partir das distribuições percentílicas de cada parâmetro, comparadas às de outros percursos e do ciclo FTP.

Neste trabalho é proposto que os instantes das mudanças de marcha e as correspondentes velocidades do veículo, sejam determinados pela relação de transmissão, dada pelo quociente "Velocidade/RPM". Esta função é formada por 
patamares característicos de cada marcha engatada, cujas variações indicam o instante da troca e a velocidade em que ocorreu, como indicado na figura 2 , sendo útil para a verificação das ocorrências em tráfego real, assim como em dinamômetro, na fase de processamento e validação dos dados.

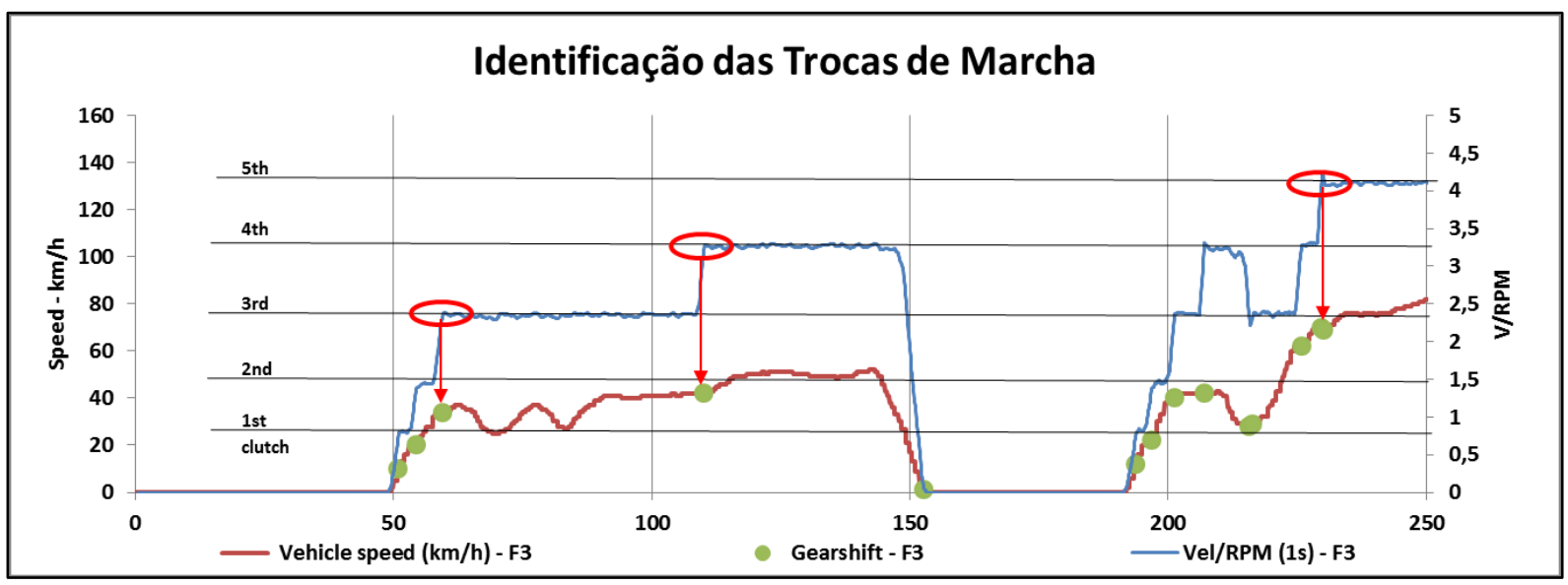

Figura 2 - Determinação dos instantes e velocidades nas trocas de marchas

Esta técnica evidencia que as trocas de marcha nos ensaios realizados segundo o ciclo FTP e em tráfego real apresentam diferenças, conforme indicado na figura 3, e demonstram claramente que o teste padronizado induz o motorista a práticas viciadas em movimentos previsíveis, que certamente se refletirão indevidamente nas emissões.
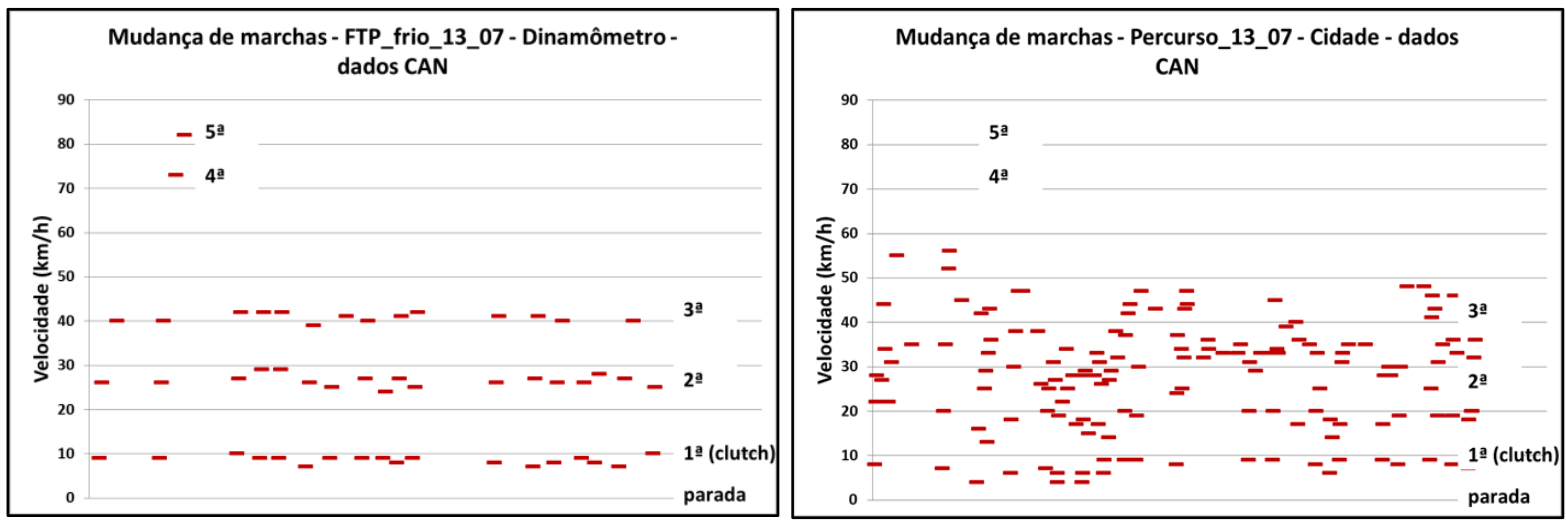

Figura 3 - Velocidades nas trocas de marchas no ciclo FTP e no trânsito

Além deste recurso, que pode ser aplicado a partir do registro das velocidades e RPM do motor, a análise das curvas da posição do pedal do acelerador e da abertura da borboleta também constituem ferramentas importantes para verificar 0 comportamento do motorista durante os ensaios e avaliar a sua representatividade em relação ao uso normal de um veículo. As curvas da posição do pedal do acelerador permite verificar se o motorista conduziu de maneira viciada ou não, seja agressiva ou suavemente, distanciando-se da normalidade. Por outro lado, a abertura da borboleta (porcentagem de abertura e tempo de resposta frente a uma 
solicitação) permite fazer a mesma comparação, mas em relação à atuação do software de controle, e neste caso, a existência de diferenças na agressividade entre os dois ensaios pode ser indicativo da atuação de um defeat device.

\subsection{Alinhamento dos dados na mesma referência de tempo}

Uma etapa importante do tratamento dos dados refere-se ao alinhamento entre as medidas feitas pelo PEMS e as informações coletadas da CAN.

A aquisição de sinais diretamente no motor e nos gases de escapamento ocorre em instantes diferentes, o que produz distorções que devem ser minimizadas através do que se chama "alinhamento" dos sinais. Tais distorções são devidas a diversos fenômenos, tais como a diferença na contagem de tempos na aquisição de dados por equipamentos diferentes, a velocidade de transporte da amostra e a mistura de gases, entre outros efeitos.

Todos os parâmetros medidos pelo PEMS apresentam a mesma defasagem, estando perfeitamente alinhados entre si, pois são baseados nos gases de escape. Da mesma forma, a potência registrada pelo PEMS é calculada indiretamente a partir do consumo de combustível, que por sua vez é calculado com base no balanço de carbono nos gases emitidos. Adicionalmente, durante o trânsito dos gases pelo tubo de escapamento, o sinal gerado no motor sofre um amortecimento que atenua a sua forma na curva temporal, além da defasagem mencionada (figura 4).

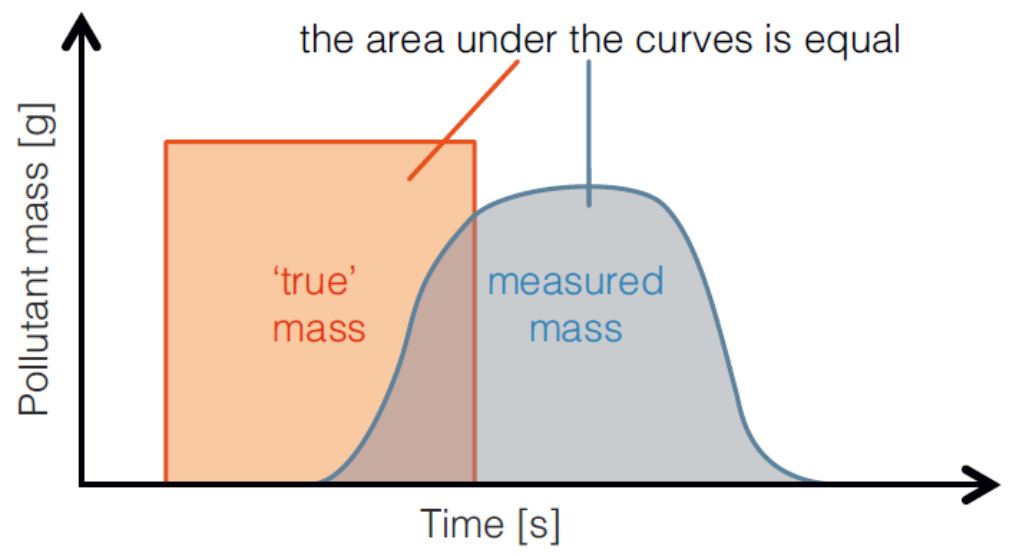

Fonte: Franco, V.G., 2014

\section{Figura 4 - Defasagem e dispersão dos sinais obtidos a partir dos gases}

Os dados coletados da CAN, por sua vez, são obtidos por sinais elétricos enviados por sensores em tempo real, de forma que não estão sujeitos aos mesmos efeitos. Assim, um pico de potência será registrado primeiro pela CAN e depois pelo PEMS, sendo necessário alinhar as duas sequências de dados e ajustar a correspondência das curvas temporais da melhor forma possível.

Tal alinhamento nunca poderá ser perfeito em toda a sequência de dados coletados, uma vez que a velocidade dos gases no tubo de escape é variável. Um primeiro ajuste pode ser feito com nitidez, buscando-se o instante em que o motor sai do 
regime de marcha lenta e começa a aumentar a rotação detectada pela CAN e ajustando ao momento em que o fluxo de descarga começa a aumentar no registro do PEMS (figura 5).

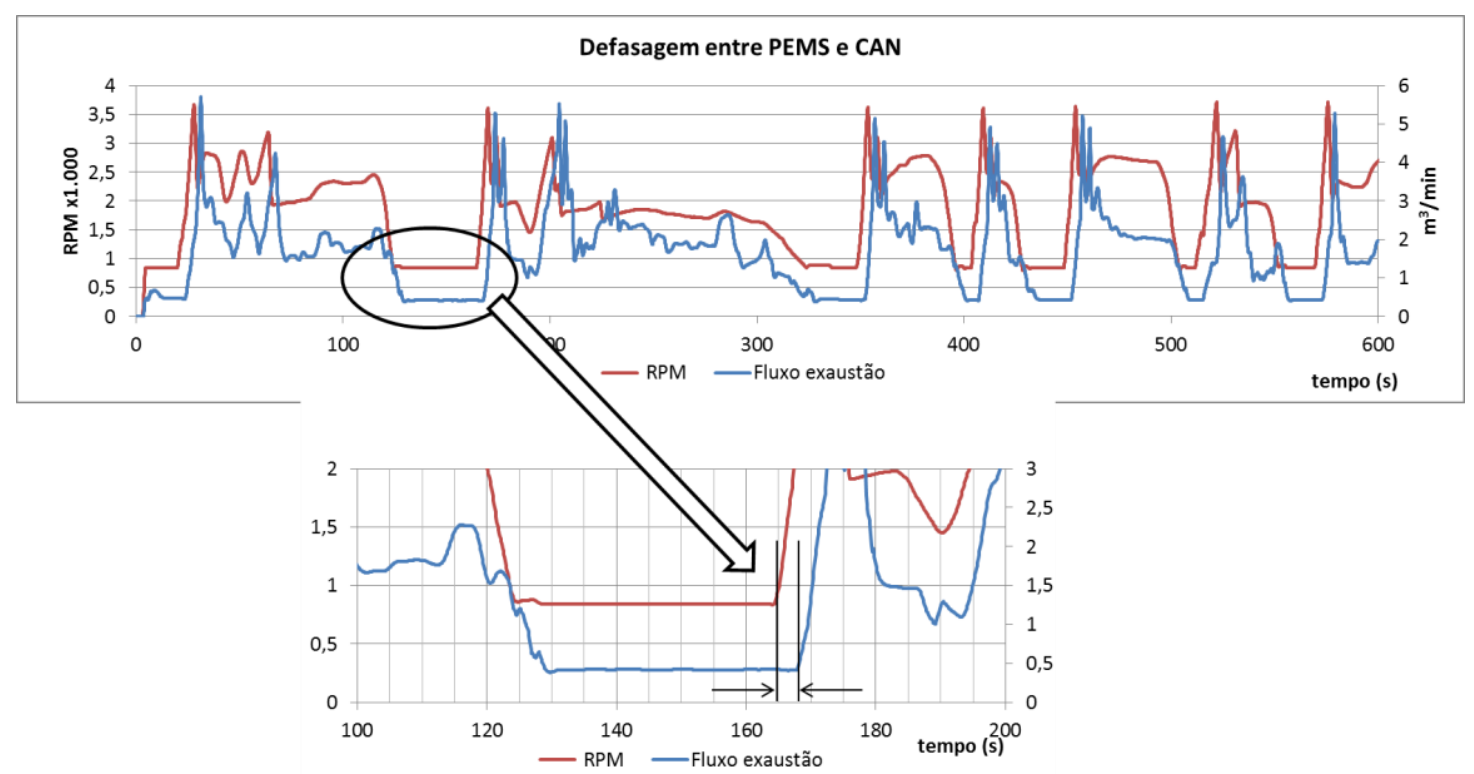

Figura 5 - Deslocamento entre as séries de dados do PEMS e da CAN

Este ajuste, entretanto, é válido principalmente para o ponto de saída da marcha lenta utilizado como base, mas apresenta desvios crescentes para as rotações mais elevadas. A maneira encontrada para refinar este ajuste é produzindo um gráfico de dispersão de parâmetros similares nas duas séries de dados (potência calculada pelo PEMS e pela CAN, por exemplo), calcular a reta de regressão entre elas e deslocar uma série de dados em relação à outra de modo a maximizar o valor de $\mathrm{R}^{2}$ (figura 6), o que resulta no melhor ajuste possível das escalas de tempo (figura 7) para a curva completa. Note-se que a curva do PEMS é suavizada pela mistura dos gases ao longo do escapamento que levam a valores médios e não aos instantâneos.

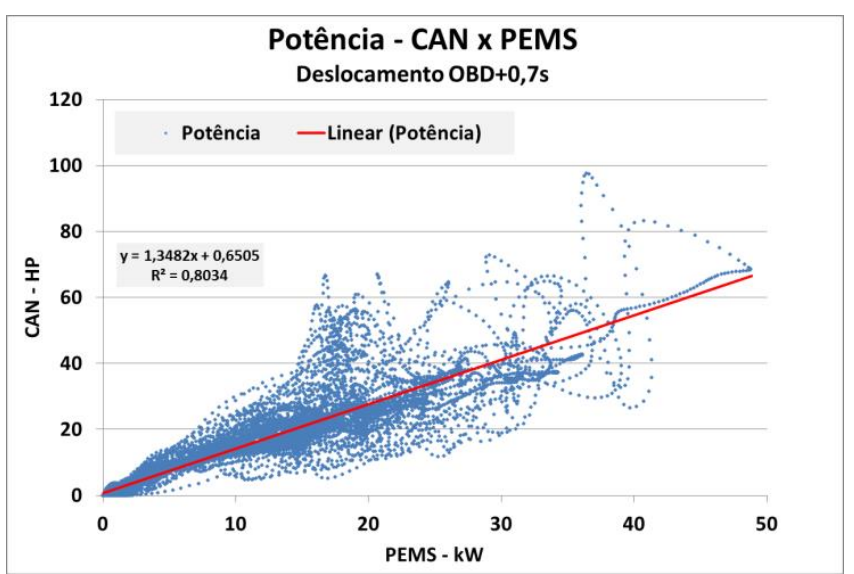

Figura 6 - Alinhamento dos dados de potência pela maximização de $\mathbf{R}^{2}$ 


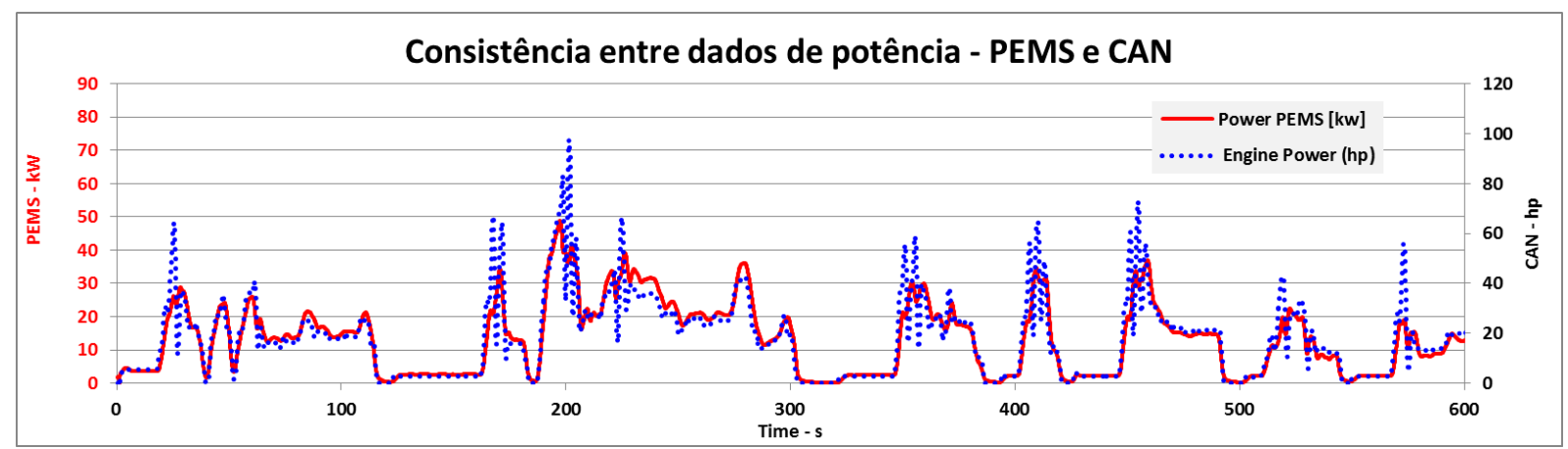

Figura 7 - Dados de potência CAN e PEMS alinhados

Somente a partir deste alinhamento será possível utilizar os dados das duas fontes conjuntamente para o cruzamento das informações e os cálculos feitos ponto-aponto entre os resultados delas. Adicionalmente, é necessário inspecionar a sequência temporal de dados de cada parâmetro para verificar a ocorrência de pontos repetidos ou "fora da curva" em decorrência de travamentos momentâneos do sistema de aquisição de dados dos equipamentos. Este é mais um problema frequentemente encontrado nos resultados finais obtidos automaticamente pelo PEMS, pois quando há travamentos prolongados, os parâmetros derivados de cálculos entre as variáveis medidas resultam completamente errados.

Quando este problema ocorre em trechos isolados e curtos, de menos de 1s, a correção dos dados por uma média móvel de 10 leituras ameniza o problema dos cálculos, mas a curva com problemas deve ser descartada em incidências maiores. A figura 8 apresenta curvas reais, onde a velocidade registrada pelo PEMS não pode ser utilizada, como demonstra a curva obtida a partir da rede CAN do veículo.

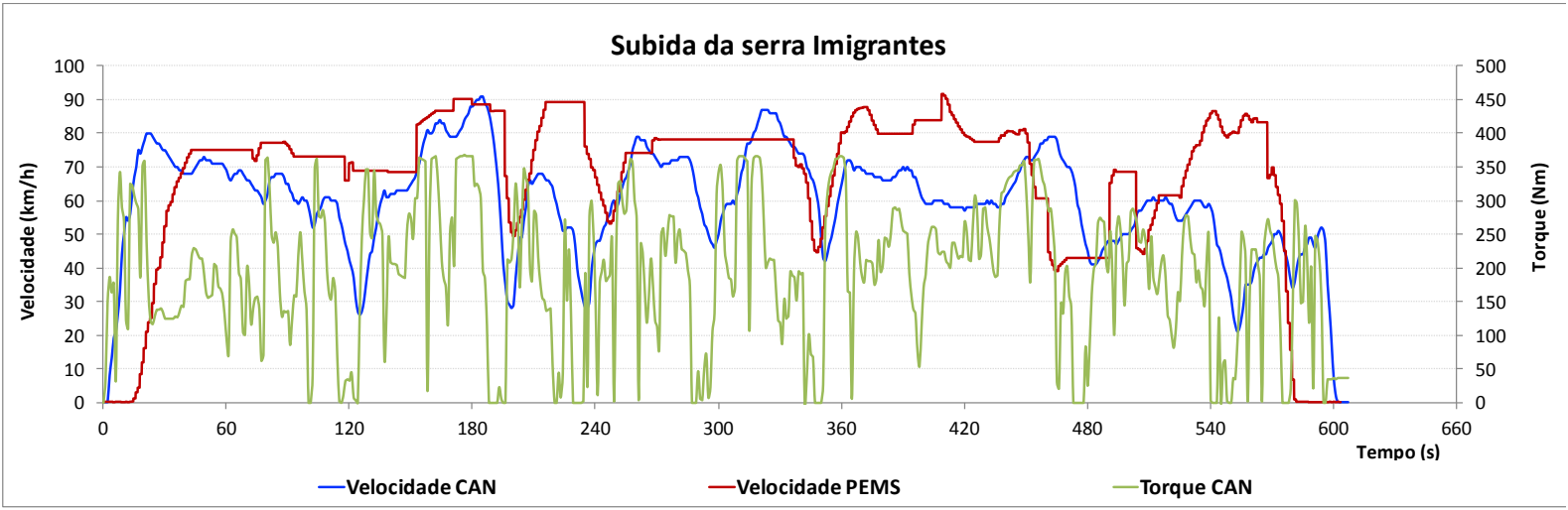

Figura 8 - Curvas temporais de um percurso com travamento do PEMS

\subsection{Reconstrução de resultados em ciclos padronizados com dados obtidos no tráfego real}

A calibração de um motor dotado de gerenciamento eletrônico compõe-se de tabelas de variáveis associadas a uma base de regimes de funcionamento definidos pelos parâmetros de torque e RPM, que são diretamente associáveis à aceleração e velocidade do veículo, respectivamente. 
conceito fundamental da reconstrução dos resultados em ciclos padronizados, a partir dos dados obtidos nas medições de emissão e consumo em tráfego real, baseia-se na determinação de valores médios para cada situação definida por um par de valores torque/RPM, ou de velocidade/aceleração, ou mesmo de outros dois parâmetros característicos escolhidos para análises específicas.

Ao contrário de depender de um percurso rigorosamente representativo dos hábitos estatísticos da sociedade, este método permite que as medições em tráfego sejam realizadas com mais liberdade, incluindo situações abusivas, para a formação de um banco de dados dos parâmetros medidos e a sua posterior classificação por regimes de funcionamento do motor e do veículo. Neste caso, os trechos de ensaios que tenham apresentado travamentos na aquisição de dados podem ser simplesmente eliminados, aproveitando-se o restante dos dados. O histograma abaixo apresenta um amplo espectro das emissões de NOx, expressas em g/s, cobrindo boa parte da gama de posições possíveis no mapa torque/RPM. Note-se que na região de cargas elevadas a emissão de NOx é significativamente mais alta em decorrência das elevadas pressões e temperaturas da combustão (figura 9).

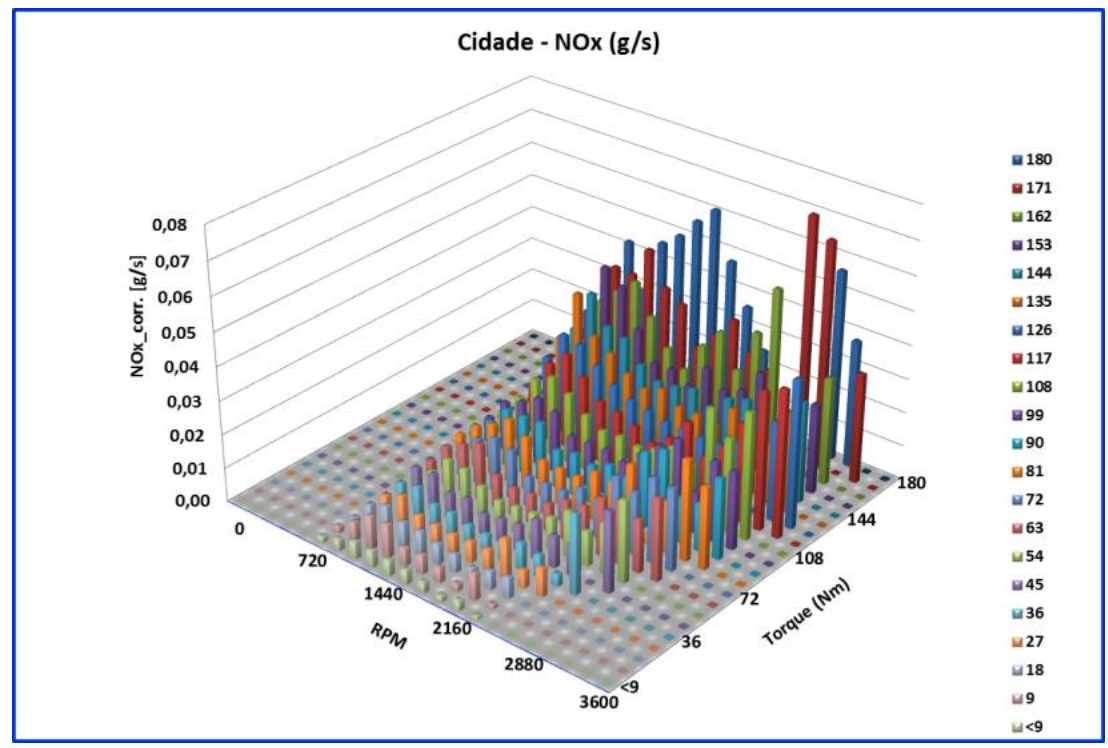

Figura 9 - Emissões de NOx no mapa de torque/RPM obtidas no trânsito real

Uma vez feita esta classificação, as médias de emissão e consumo obtidas em cada regime de funcionamento devem ser somadas, porém afetadas da ponderação pela frequência de ocorrência destes regimes no ciclo padronizado oficial, caracterizada no histograma da figura 10 , em $\%$ do tempo dispendido em cada regime de funcionamento do motor.

Desta forma, o resultado obtido independe da escolha do percurso de teste e permanece estritamente vinculado ao ciclo de condução previsto legalmente, entretanto, sob as condições reais de tráfego, levantadas de forma isenta da possibilidade de reconhecimento do ensaio pelo veículo para a atuação de um "defeat device". 


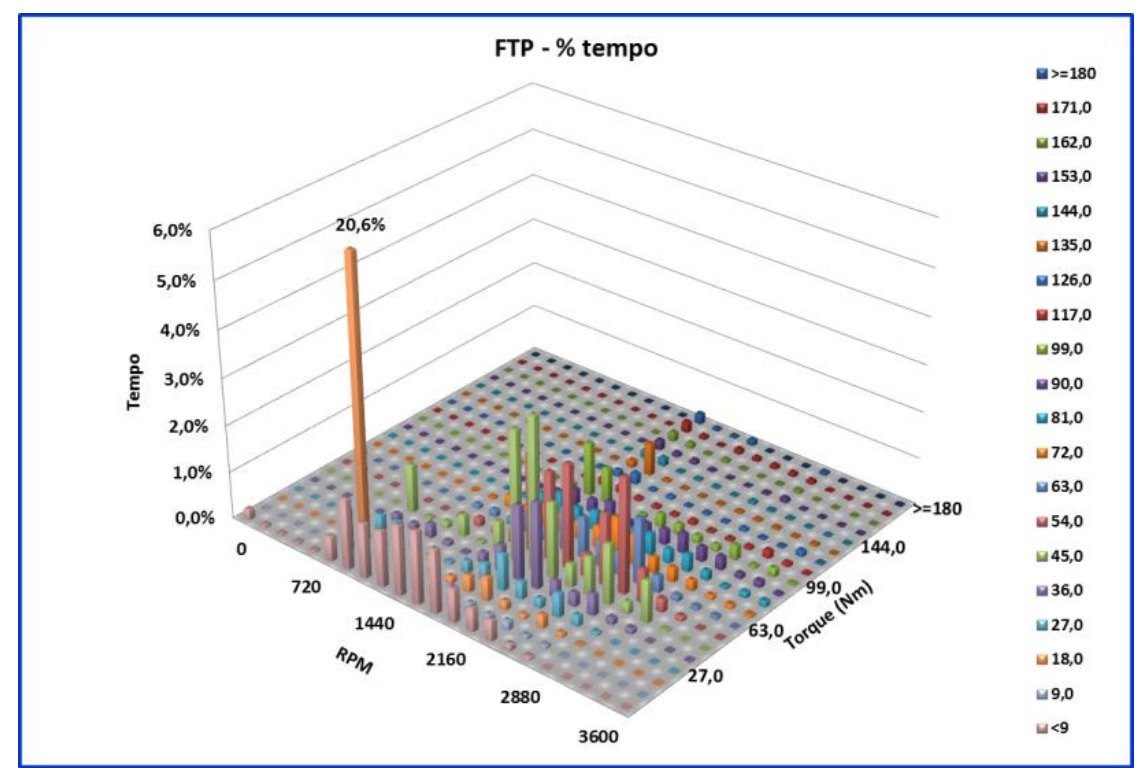

Figura 10 - Distribuição de tempos no mapa de torque/RPM no ciclo FTP

O mapa final da emissão de NOx neste motor sob as condições de tráfego é obtido pela multiplicação dos valores de cada célula em correspondência nos dois histogramas anteriores, resultando no histograma seguinte (figura 11), cuja soma será a massa total da emissão de NOx que seria obtida em um ensaio de laboratório segundo o ciclo FTP, mas com os valores de emissão obtidos em trânsito real. Caso o ensaio realizado nas ruas não englobe todos os regimes de funcionamento presentes no ciclo oficial, novos percursos devem ser escolhidos visando a cobertura de tais regimes para a complementação do banco de dados, até que toda a região do mapa do motor percorrida no ensaio oficial esteja devidamente coberta. Inversamente, solicitações eventualmente abusivas realizadas em percursos severos produzem resultados válidos que são utilizados com a ponderação existente no ensaio oficial, sem comprometer os resultados finais.

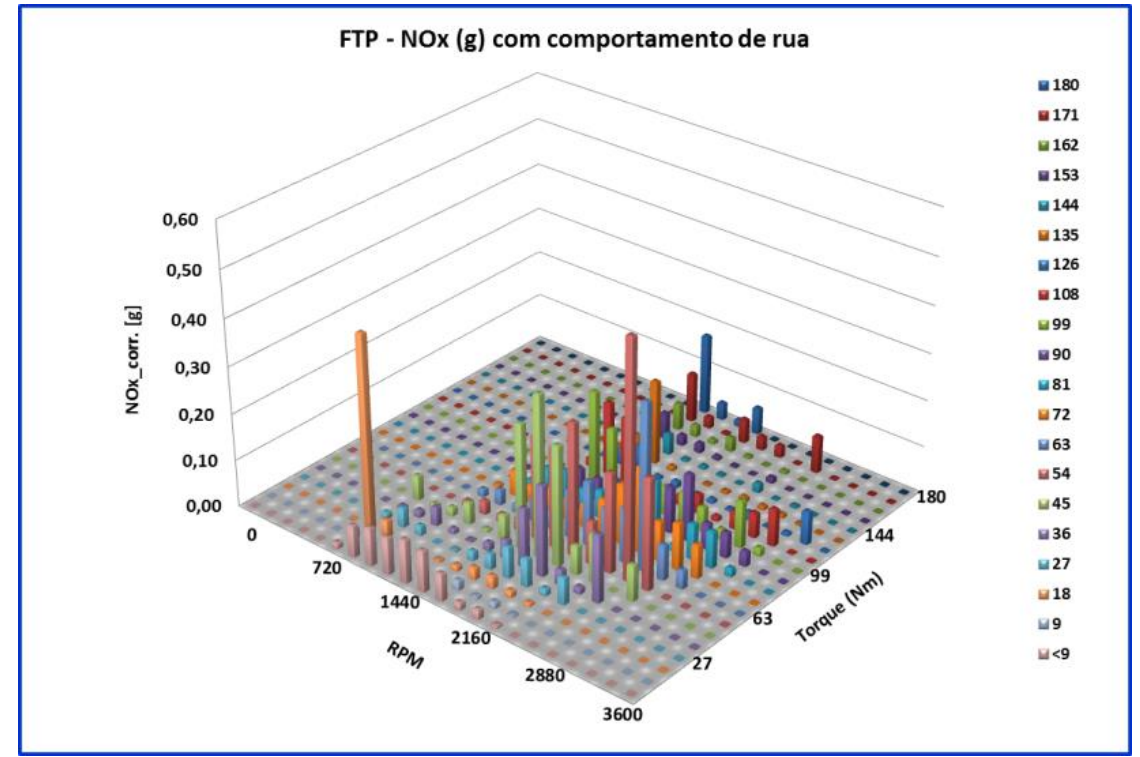

Figura 11 - Massa de NOx emitida em trânsito real convertida para o ciclo FTP 
Um aspecto muito importante na aquisição de dados para a montagem desses histogramas é a validação estatística de cada resultado atribuído a um ponto do mapa definido pelo par torque $x$ RPM.

As funções e parâmetros dos sensores e atuadores são definidos digitalmente em tabelas do mapa do motor, isto é, para cada regime identificado pelo torque e RPM, em condições de referência. Estas calibrações básicas são continuamente otimizadas por coeficientes de correção em função das condições reais momentâneas de pressão atmosférica, temperaturas do ar e do motor, velocidade e sentido do acionamento do acelerador, pressão real do turbo, taxa real de EGR, concentração de oxigênio nos gases de escapamento e outros parâmetros, considerando também o ajuste da suavidade na condução ou dirigibilidade.

Como resultado, os mapas dos parâmetros de saída são variáveis no tempo, que devem ser verificados nos ensaios de conformidade e busca de defeat devices, sendo que cada situação, definida pelo torque e RPM, apresenta uma variação estatística associada, decorrente das condições instantâneas de utilização do veículo e da sequência de regimes imediatamente anterior. A figura 12 apresenta estas distribuições estatísticas para quatro regimes característicos, identificados no mapa do motor, definido por uma matriz $20 \times 20$, conforme mostrado nos histogramas anteriores.

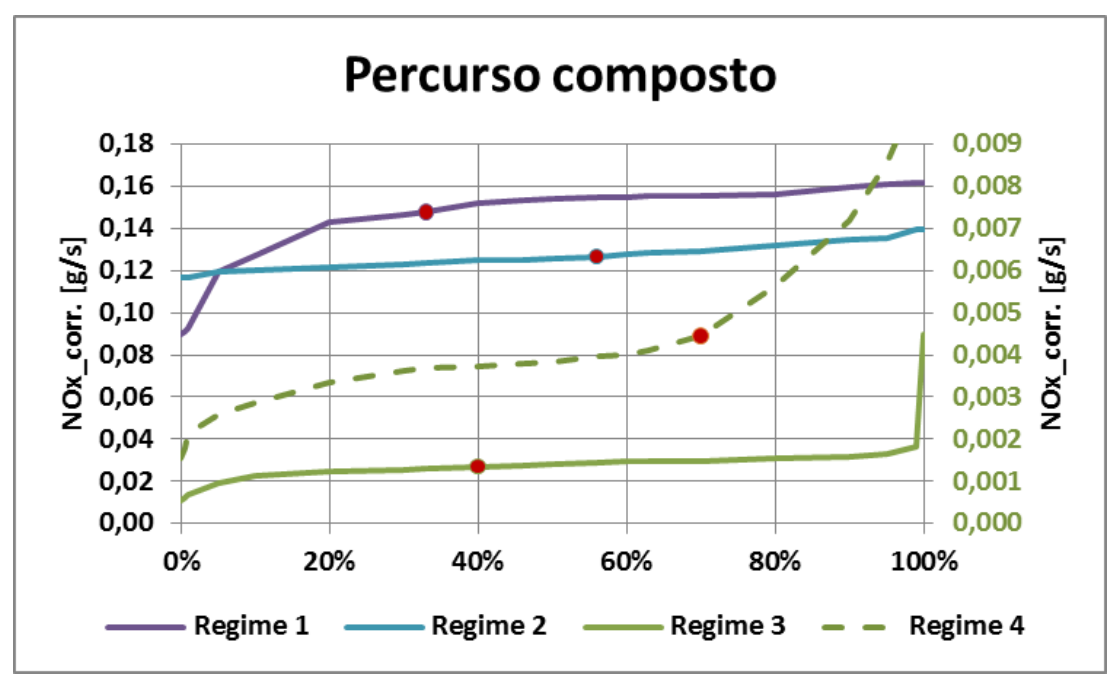

Figura 12 - Variações estatísticas observadas em diversos regimes de funcionamento

Nestas estatísticas os valores de médias e medianas mostraram-se próximos, justificando a adoção de uma ou outra como o parâmetro representativo em cada regime considerado para efeito de caracterização das emissões. Este critério deve servir de base para a validação do banco de dados de regimes caracterizados para a construção do mapa do motor, indicando o número mínimo de medições que deve existir para cada par de parâmetros.

Eventos muito rápidos que modifiquem o comportamento do motor apenas em períodos inferiores ao tempo de amostragem $(0,1 \mathrm{~s})$ serão atenuados, ou mesmo 
eliminados, ao figurarem em conjunto com outros pontos pertencentes ao mesmo intervalo de amostragem. Entretanto, este aspecto é desejável, porque a individualização de tais eventos poderia classifica-los como pertencentes a um regime à parte e deixa-los de fora do cálculo da emissão no ciclo de condução. $O$ fato de a ocorrência de picos de emissão de alta frequência ter pequena influência no fluxo médio emitido, também justifica que os eventos de alta frequência não sejam individualizados, mas permaneçam considerados nas médias dos parâmetros tomadas a $10 \mathrm{~Hz}$.

\subsection{Resultados com mapas alternativos e proxies dos parâmetros da CAN}

Uma análise mais profunda da calibração do motor e seus controles de emissão requer a utilização de novos parâmetros complementares, que foram definidos e calculados a partir dos dados levantados para a avaliação do comportamento do motor, comparando-o entre diversos ensaios diferentes. A comparação entre os comportamentos de laboratório e de trânsito real não pode ser resumida às situações de mesmas velocidades e acelerações, mas devem ser traduzida em situações semelhantes de quaisquer parâmetros relevantes, tais como força na roda, torque do motor, pressão média efetiva, consumo de combustível e emissões.

A força na roda, calculável a partir da velocidade, inclinação da pista e fatores do coast down é o parâmetro mais imediatamente relacionado à carga imposta ao veículo e, portanto, ao torque do motor. Entretanto, como a medida de altitude pelo GPS é muito imprecisa para esta finalidade, o uso desse parâmetro fica muito restrito.

Um parâmetro alternativo, que corresponde a uma força fictícia proporcional às forças na roda e produz comparações úteis, é a "força motriz indicada", que independe das frenagens e oscilações devidas à flutuação inercial. Este parâmetro é determinado termodinamicamente a partir da potência indicada fornecida pelo PEMS e da velocidade, a menos da eficiência da transmissão, que pode ser tomada como uma constante próxima da unidade para este efeito. Neste caso, os cálculos a partir dos dados da CAN produzem picos muito elevados e valores um pouco superiores aos do PEMS, que parecem mais realistas.

$$
F_{\text {motriz }}=\frac{3600 * \eta * \text { Potência }[\mathrm{kW}]}{V e l[\mathrm{~km} / \mathrm{h}]}
$$

O torque do motor é um parâmetro indireto, calculado termodinamicamente a partir do consumo instantâneo de energia tanto na CAN quanto no PEMS.

O fluxo de combustível, calculado a partir do balanço de carbono, é um parâmetro importante indicador da carga instantânea do motor. As emissões medidas pelo PEMS, expressas em $\mathrm{g} / \mathrm{s}$, também constituem parâmetros importantes para caracterizar as quantidades de poluentes produzidas, entretanto este parâmetro apresenta grandes variações e picos elevados, dificultando a visualização dos comportamentos do motor. 
A associação do fluxo de combustível aos de emissões, permite o cálculo das emissões instantâneas em gramas de poluente por quilograma de combustível consumido. Estes parâmetros são bastante estáveis em todo o mapa (uma vez que a geração de poluentes é em grande medida proporcional ao consumo de combustível) e representam indicadores importantes do padrão tecnológico do veículo, sendo essenciais para a comparação de regimes do motor com medições em dinamômetro, expressas em $\mathrm{g} / \mathrm{kWh}$ e nas fiscalizações em massa por sensoriamento remoto vii (Bishop, G.A. et al, 2015), também expressos em g/kg, sendo um dos melhores parâmetros para caracterizar a resposta do motor às condições de funcionamento. Esta técnica permite uma ampla gama de comparações, desde testes de desenvolvimento de veículos ou motores em laboratório, veículos em percursos de trânsito real, ou frotas de veículos que passem por um mesmo ponto de fiscalização, ou ainda entre motores de classes e tamanhos diferentes (de veículos leves e pesados).

Como o objetivo final deste trabalho é propor um método para a detecção de fraudes, é necessário complementá-lo com a busca de parâmetros de referência que não envolvam o acesso direto à $\mathrm{CAN}$, pois a simples conexão com a mesma poderia servir, no futuro, como chave para o reconhecimento da condição de ensaio e acionar algum defeat device. Neste sentido, foram buscadas variáveis que se comportassem como proxies da RPM e do torque, como uma aproximação. Para efeitos práticos, a RPM pode ser bastante bem representada pelo fluxo de gases de escape, com a qual tem relação direta, e o torque, por sua vez, é intrinsecamente relacionado à pressão média efetiva (PME), definida como:

$$
P M E=\frac{\text { Trabalho no ciclo }}{\text { volume deslocado }}=K * \frac{\text { Potência }}{R P M * \text { Cilindrada } / 2}=\frac{\text { Potência }}{\text { Vazão teórica de gases }}
$$

Esta proxy, quando obtida a partir da potência e do fluxo de gases dados pelo PEMS, resulta num novo parâmetro aproximado que denominamos "pressão média PEMS" (PME ${ }_{\text {PEMS }}$ ), que apresentou boa correlação com o comportamento do torque informado pela CAN.

Com estas proxies, os ensaios de campo podem ser realizados duas vezes, sendo uma com o contato com a CAN, para maior abrangência da interpretação dos parâmetros do motor, e outra somente com o PEMS para a verificação dos resultados baseados as proxies em ambos os casos. A aderência elevada dessas estatísticas afastaria a hipótese de uma fraude a partir da conexão com o OBD e os mapas baseados nos parâmetros baixados diretamente do motor poderiam então ser utilizados com segurança para comparações mais precisas, como o par torque/RPM. Esta técnica também permite admitir que estas proxies estejam naturalmente alinhadas com as emissões por serem calculadas a partir do fluxo de gases como todos os parâmetros envolvidos na determinação da potência e do consumo.

Além destes pares de parâmetros base, outros também permitem avaliações interessantes sob ângulos conceituais que podem complementar a análise de um veículo. Dentre os mapas complementares, podemos destacar os seguintes: 
a) PME-RPM: é o substituto do mapa torque-RPM, com a vantagem de que reduz todos os motores a uma base comum associada à agressividade do motor independentemente do seu tamanho. Depende da conexão com a CAN para a aquisição dos dados de RPM.

b) PME-velocidade: é a variante mais imediata do mapa do motor, referida à velocidade do veículo, já sob influência da troca de marchas. Depende da conexão com a CAN para a aquisição dos dados de RPM para o cálculo da pressão média efetiva.

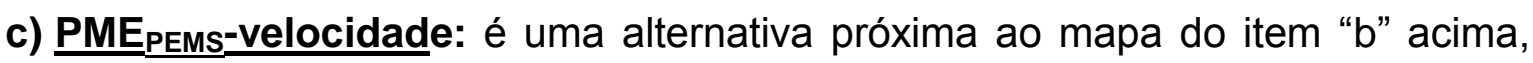
porém de cálculo independente da conexão com a CAN, pois baseia-se na vazão de escapamento medida diretamente pelo PEMS.

d) Velocidade-forca na roda: é o mapa do veículo, homólogo ao torque-RPM, que permite a comparação mais próxima entre as condições do movimento existentes no ciclo padrão e nos trajetos de rua. Independe da conexão com a CAN, mas depende da medição precisa das inclinações da pista para não introduzir desvios muito grandes.

e) Velocidade-potência na roda: é um mapa do veículo alternativo ao anterior que atenua os desvios do cálculo da força na roda por multiplicá-la por velocidades próximas de zero onde os desvios ocorrem. Pode ser uma opção se os parâmetros mecânicos forem preferidos.

f) Velocidade-forca motriz: é uma alternativa segura aos dois mapas anteriores, calculada a partir da potência indicada e da velocidade do veículo. Também é um parâmetro que independe da conexão com a CAN e da inclinação da pista.

g) Velocidade-aceleração do veículo: quando o interesse for a previsão de resultados em um ciclo de condução alternativo no qual o veículo ainda não foi ensaiado e, portanto, não se dispõe da distribuição estatística dos tempos que o veículo permanece em cada regime considerado, o mapa velocidade $x$ aceleração é uma alternativa que pode substituir os mapas anteriores, por ser calculado apenas a partir da curva de velocidades que define o ciclo. A aceleração do veículo corresponde à força na roda, porém não considera a inclinação da pista, mas permite uma previsão razoavelmente segura a partir dos resultados obtidos em um percurso de rua. Também é um parâmetro que independe da conexão com a CAN e da inclinação da pista.

\section{Exemplos de resultados obtidos}

Com a aplicação das técnicas descritas, os resultados obtidos podem ser apresentados sob a forma de histogramas para descrever o comportamento de um veículo ou motor, comparado em situações diferentes de solicitação. Tais análises podem contemplar as emissões, o consumo de combustível ou parâmetros do gerenciamento do motor, como mostram as figuras a seguir na base "torque x RPM", comparando as emissões de NOx de um veículo leve, com motor Diesel turbo alimentado, no ciclo FTP fases 1 e 2 e em um percurso em tráfego real.

É importante notar que os valores intermediários do fluxo de NOx são maiores quando operando no trânsito, devido à variabilidade das forças atuantes, porém os picos são praticamente os mesmos. Além disso, os resultados não apresentam 
descontinuidades de comportamento que possam indicar a ocorrência de fraudes voltadas aos regimes presentes no ciclo padronizado (figura 13).

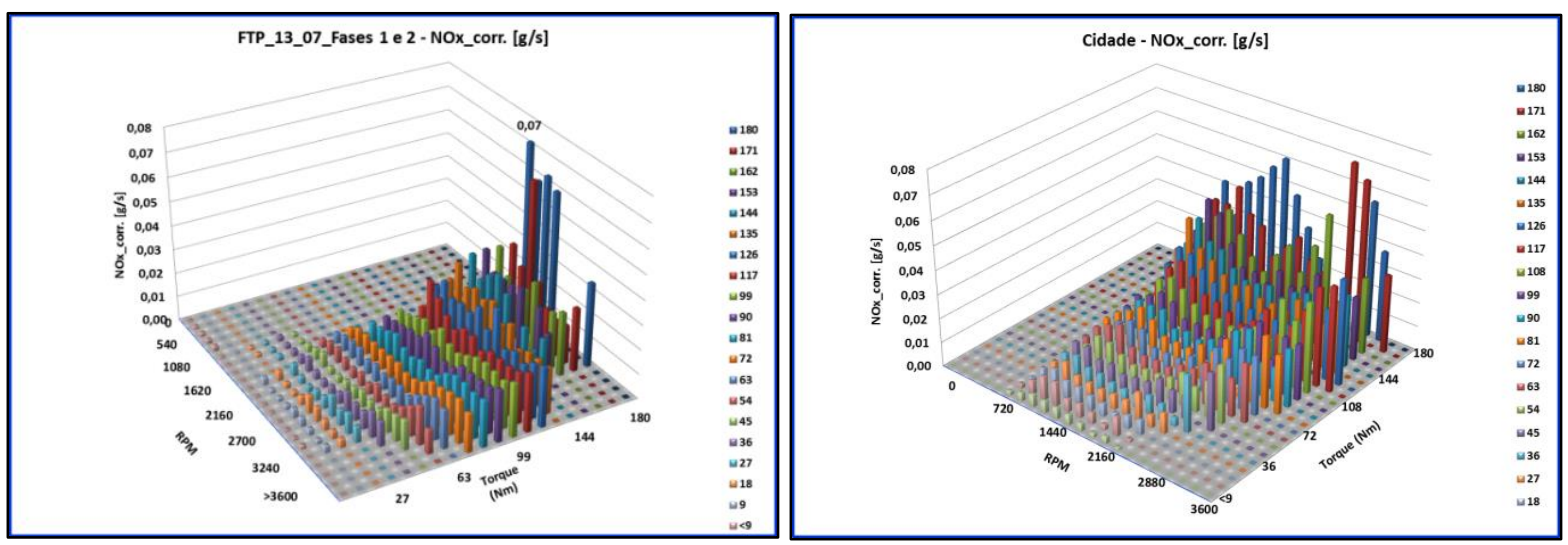

Figura 13 - Histogramas dos fluxos da emissão de NOx (g/segundo) no mapa RPM x Torque

Comportamento semelhante ocorre na emissão específica de NOx, conforme mostrado na figura 14, indicando a inexistência de defeat devices neste caso. É importante observar que a emissão específica, expressa em $\mathrm{g} / \mathrm{kg}$ _combustível é mais uniforme ao longo de todo o mapa do motor, permitindo uma análise mais clara da resposta deste motor à tecnologia empregada na sua calibração, cuja média resultou entre 5 e $20 \mathrm{~g} / \mathrm{kg}$ _combustível ou 1,3 a 1,7 g/kWh.

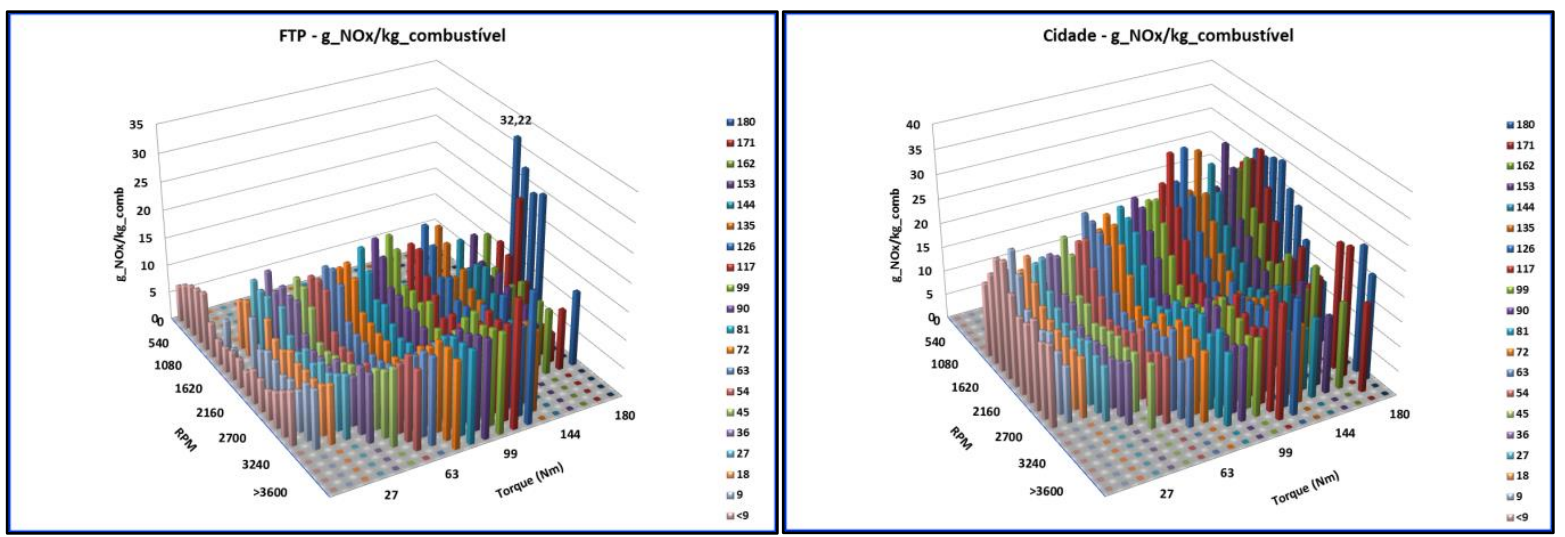

Figura 14 - Histogramas das emissões específicas de NOx (g/kg_combustível) no mapa RPM x Torque

A comparação destes dois bancos de dados, levantados nas condições do ciclo FTP em laboratório e em um trajeto na cidade, já permitem uma análise bastante ampla, entretanto ainda há regimes de funcionamento que ocorreram no FTP que não apareceram no trajeto real, exigindo que o levantamento seja estendido a novas situações.

Complementando-o com novos trajetos e movimentos propositalmente realizados, inclusive numa subida de serra, na busca de solicitações mais severas presentes em alguns pontos do FTP, foi possível compor a totalidade das combinações para 0 
cálculo das emissões ponto-a-ponto em toda a área de interesse do mapa do motor com as emissões medidas em tráfego real, ponderadas pelos pesos dados pelas frequências de ocorrência no FTP.

Para este veículo foram constatados aumentos de emissão de NOx de $52 \%$, compatível com as exigências futuras da Diretiva Europeia e coerentes com as diferenças entre as condições de laboratório e as encontradas em vias públicas.

\section{Conclusões}

A técnica de análise descrita neste trabalho permite comparações objetivas de comportamentos de quaisquer parâmetros de interesse para caracterizar as respostas de um motor ou veículo em situações de funcionamento diversas para a avaliação da sua calibração em correspondência com o consumo de combustível e a emissão de poluentes, segundo as solicitações de carga e velocidade. Será necessário ampliar o número de veículos ensaiados segundo a metodologia apresentada neste trabalho para o conhecimento das faixas de variação dos resultados que possam ser definidas como aceitáveis ou mesmo esperadas para cada poluente a para o consumo de combustível.

Considerando que os defeat devices baseiam-se na identificação de padrões que caracterizam os ensaios de certificação, os processos para a sua detecção precisam necessariamente ir além de qualquer procedimento padronizado, improvisando comparações à luz dos recursos tecnológicos mais recentes aplicados ao gerenciamento do motor e do veículo como complemento dos procedimentos oficiais de certificação.

Os ensaios complementares aos oficiais atuais precisam ser dotados de novos critérios e aprimoramentos que avaliem a representatividade das condições de teste a partir das respostas do veículo, com a isenção necessária para considerar as condições extremas de teste apenas na devida proporção de ocorrência no tráfego real, sejam elas abusivas ou favoráveis. Tais critérios devem necessariamente incluir ensaios não padronizados, em vias públicas com o veículo em trânsito real, para que todas as condições usuais estejam incluídas no movimento, e contribuam para que os resultados do ensaio e sua interpretação sejam de fato representativos do uso normal.

É importante que este procedimento garanta que sejam afastadas quaisquer possibilidades de viés que possam servir de "senhas para o reconhecimento da condição de teste", inclusive a conexão de equipamentos com a rede CAN do veículo. Para isso, deve-se incluir uma análise baseada em resultados obtidos exclusivamente a partir dos gases medidos pelo PEMS, cujos mapas podem ser construídos com a PME PEMS $_{\text {e }}$ o fluxo de gases de escapamento, que são boas proxies do par torque-RPM.

Os ensaios em via pública devem ser compostos por movimentos representativos do tráfego real e também do ciclo de condução padronizado, que é assumido como tal pela própria regulamentação.

A busca por um defeat device deve incluir uma análise mais profunda da calibração do motor e seus controles de emissão, o que requer a utilização de parâmetros 
adicionais, comparando os comportamentos do motor em ambas as condições, de laboratório e em trânsito real.

Parâmetros ambientais (ventos, buracos e inclinações da pista), assim como hábitos de condução (momento de troca de marchas, acelerações bruscas etc.) constituem diferenças importantes entre os ensaios em ciclos padronizados em dinamômetro e os realizados nas ruas. Estas interferências geralmente aumentam a carga do motor e, consequentemente, as emissões e o consumo de combustível.

Os percursos reais escolhidos para a realização dos ensaios devem ser previamente validados como representativos, em função da sua distribuição estatística conjunta de velocidades e acelerações, num histograma tridimensional.

É imprescindível a verificação da ocorrência de "travamentos eletrônicos" na aquisição de dados. Trechos curtos e isolados podem ser ajustados por médias móveis com abrangência de 1 segundo, mas travamentos prolongados devem ser eliminados antes de comporem o banco de dados do veículo, ou o ensaio descartado.

A comparação das curvas temporais dos parâmetros obtidos simultaneamente pelo PEMS e pela CAN é de extrema importância para a validação e alinhamento de todos os dados. Os mais significativos são o fluxo de combustível calculado pelo PEMS e o indicado pela CAN, assim como a vazão de ar (CAN) em correspondência com o fluxo de escapamento (PEMS).

As emissões expressas como gramas de poluente por quilograma de combustível permitem avaliar a uniformidade do comportamento do motor em todos os regimes de funcionamento, bem como comparações válidas importantes entre motores de classes e tamanhos diferentes (de veículos leves e pesados) e também entre ensaios completamente diversos, como é o caso dos levantamentos em frota por sensoriamento remoto.

A comparação mais justa e objetiva dos resultados em trânsito normal com os medidos em laboratório envolve a associação de mapas, com as médias de emissão levantadas em campo para cada regime, e as frequências de ocorrência desses regimes no ciclo FTP (ou em qualquer outro ciclo padronizado), a qual permite recriar por cálculo a determinação da emissão no ciclo regulamentado, mas com o veículo funcionando nas condições de tráfego real.

O torque e a RPM são os parâmetros mais adequados à caracterização do comportamento do motor e à montagem dos mapas de resultados, visto que estes constituem a base da definição da sua calibração e estes mapas podem ser

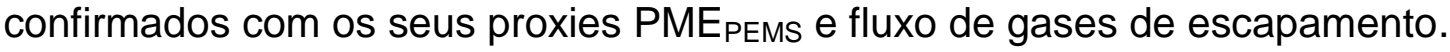

Para que o controle de emissões no Brasil prossiga no caminho trilhado pela Europa e EUA, será necessário dotar a legislação nacional não apenas de novos limites mais restritivos, mas também dos procedimentos de avaliação utilizados neste estudo e daqueles utilizados para o monitoramento da frota em larga escala por sensoriamento remoto para evitar no Brasil a ocorrência das fraudes detectadas naqueles países, tanto para os veículos leves quanto para os pesados. Desta forma será possível estabelecer uma estratégia confiável de redução das emissões e coerente entre as diversas categorias de veículos e as necessidades ambientais. 


\section{Referências Bibliográficas}

i https://www.dieselnet.com/standards/cycles/ttp75.php

ii IBAMA, 2011 - Programa de controle da poluição do ar por veículos automotores - Proconve/Promot//bama, 3 ed. — Brasília: Ibama/Diqua, 2011. 584 p.

iii Franco, V.G., 2014 - Evaluation and improvement of road vehicle pollutant Emission factors based on instantaneous emission data processing - tese de doutorado; Escola de Tecnologia e Ciências Experimentais, Ispra (Itália) - Castelló de la Plana (Espanha) - Junho 2014

iv União Europeia. Regulamento (UE) 2016/427. Consultado em 29/mai/2017 em http://eur-lex.europa.eu/legal-content/PT/TXT/?uri=CELEX\%3A32016R0427 .

${ }^{\vee}$ EPA, 2016 - Code of Federal Regulations, title 40, chapter I, subchapter C, part 86. Consultado em 29/mai/2017 em https://www.ecfr.gov/cgi-bin/text-

idx?SID=63fe509902b3249e679491edd73bdcd3\&mc=true\&node=pt40.21.86\&rgn=di v5\#se40.21.86_11809_610

vi Tutuianu, M.; Bonnel, P.; Ciuffo, B.; Haniu, T.; Ichikawa, N.; Marotta, A.; Pavlovic, J. \& Steven, H., 2015 - Development of the World-wide harmonized Light duty Test Cycle (WLTC) and a possible pathway for its introduction in the European legislation. Transportation Research Part D: Transport and Environment, volume 40, Outubro 2015, P. 61-75.

vii Bishop, G.A.; Hottor-Raguindin, R.; Stedman, D. H.; McClintock, P.; Theobald, E.; Johnson, J.D.; Lee, D-W.; Zietsman, J.; Misra, C., 2015 - On-road Heavy-duty Vehicle Emissions Monitoring System - Environmental Science and Technology, 49, 1639-1645 